\title{
Fish Farmers' Willingness to Pay for Improved Information and Communication Technologies During COVID-19: A Case of Ibadan, Nigeria
}

\author{
Selorm Omega ${ }^{1}$, Esther E. E. Adebote ${ }^{2}$, Peter K. Omega ${ }^{3}$, Selorm Akaba ${ }^{1} \&$ Omitoyin A. Siyanola $^{4}$ \\ ${ }^{1}$ Department of Agriculture Economics and Extension, University of Cape Coast, Ghana \\ ${ }^{2}$ Nigerian Institute for Oceanography and Marine Research, Victoria Island, Lagos, Nigeria \\ ${ }^{3}$ Ministry of Food and Agriculture, Cape Coast, Ghana \\ ${ }^{4}$ Department of Aquaculture and Fisheries Management, University of Ibadan, Ibadan, Nigeria \\ Correspondence: Selorm Omega, Department of Agriculture Economics and Extension, University of Cape \\ Coast, Cape Coast, Ghana. Tel: 233-545-022-814. E-mail: selorm.omega@stu.ucc.edu.gh
}

Received: September 9, 2021

doi:10.5539/jas.v14n2p113
Accepted: November 28, $2021 \quad$ Online Published: January 15, 2022

URL: https://doi.org/10.5539/jas.v14n2p113

\begin{abstract}
Coronavirus has disrupted aquaculture activities at all levels. The pandemic has had effect on farmer's input, output, market, revenue, and contact with Extension officers. To reduce the growing effect of the pandemic, the use of Information Communication Technologies has become necessary as farmers can get easy access to extension agents and monitor farm activities while reducing exposure to the virus. Hence, this research was conducted to determine fish farmer's willingness to pay for improved Information Communication Technologies in bridging the gap caused by the Coronavirus outbreak. The study used cross-sectional survey with data collected from Ibadan, Nigeria. Simple random sampling technique was used to select a sample size of 40 farmers. Primary data was analysed using StataSE13.0 and the results revealed that; $80 \%$ of farmers were affected by Coronavirus and acknowledged that Information Communication Technologies play a role in their activities (55\%). The probit regression revealed that the scale of operation, age of farmer, household size, status in the household, and usage of Information Communication Technologiess were found to be statistically significant determinants of farmer's willingness to pay. These points to the fact that improved Information Communication Technologies are relevant to sustain aquaculture output in the face of Coronavirus. The study recommends that the government, the ministry for aquaculture, and stakeholders in aquaculture should support small-scale in the form of training, credit and provision of support systems to help them acquire and use improved ICTs.
\end{abstract}

Keywords: probit, ICTs, COVID-19, willingness to pay

\section{Introduction}

As a result of the outbreak of Coronavirus (COVID-19), which affected virtually all sectors of the Nigerian economy, the aquaculture sub-sector was also heavily affected by the pandemic. The effect of COVID-19 has been felt by farmers, as their market has dwindled and revenue margin lowered as a result of the impact on demand and supply. They face several obstacles, including farmers' restricted access to input and consumer markets and contact with extension agents. One of the pandemic prevention strategies advocated by the National Centre for Disease Control (NCDC) was social distancing, which discourages large-scale access to market/marketing. These necessitated the need for farmers to have Information Communication Technologies (ICTs) to bridge the gap created by getting their markets and extension needs closer than ever before.

The adoption of ICTs has created great opportunities for growth in the agricultural sector (Getahun, 2020). Farmers that can adopt ICTs that are relevant and economical to their fish farming businesses are likely to sustain growth and be able to compete effectively (Chavula, 2014). ICTs have been shown to promote technological adoption, to provide information on new seed varieties, inputs, and information on new products and market prices at a reasonably low cost. The ICT sector has seen a high level of progress in the agricultural sector and its development has gradually improved over the last decades (Otsuka, Kijima, \& Serunkuuma, 2011). 
Agricultural and food industries in many countries, multinational farm input businesses, and even small and medium-sized farm input suppliers offer a range of ICT services to farmers, including extension advice (FAO, 2017). In developing countries, high transaction and maintenance costs has been identified as a major challenge to ICT services adoption and usage by farmers. However, ICTs have the potential to reduce these costs, improve market access and increase the chance of farmer's extension needs being met.

\subsection{Research Objectives}

Hence, this research was conducted to,

(1) identify areas of farm operations and ICTs used by fish farmers during COVID-19;

(2) examine fish farmers level of ICTs usage during COVID-19;

(3) examine amount fish farmers were willing to pay for improved ICTs during COVID-19;

(4) predict factors that influence fish farmer's willingness to pay for improved ICTs during COVID-19.

\subsection{Research Hypothesis}

$\mathrm{H}_{0}$ : There is no significant relationship between improved ICTs fish farmers are willingness to pay for and scale of operation.

\section{Materials and Methods}

The research used a cross-sectional survey design. Cross-sectional survey design was used because the data for the study was collected at one point in time. The design also allows for the comparison of different variables at the same time. In this study the use of cross-sectional survey design helped to find out the causal relationship between willingness to pay and independent variables such as socioeconomic characteristics, ICT usage, extent and effectiveness. The study area was Ibadan in Oyo State, Nigeria. Ibadan is the capital of Oyo state. The Oyo state has a land area of approximately $10,986 \mathrm{~m}^{2}$. Its fine climate (equatorial) condition of both dry (November to March) and wet seasons (April to October) coupled with high humidity and average temperature range of 25 ${ }^{\circ} \mathrm{C}$ and $35^{\circ} \mathrm{C}$ yearly makes it a fish farmable area. The topography of the area is made up of old hard rocks with dome-shaped hills on the Southern part rising 500 meters to 1,200 meters on the Northern part of the state. The research adopted the simple random sampling technique in selecting 40 respondents for the study.

A structured questionnaire was used for the data collection. The questionnaire was grouped in three part with the first being the socioeconomic characteristics of fish farmers. Socioeconomic variables collected included; age, sex, scale of operation, ethnicity, access to credit, religion, status, farm size, household size, years of education and years of farming experience. The second part asked farmers' questions on the ICTs used, the extent of use, and the effectiveness of these ICTs in their activities in the face of COVID-19. The third part looked at what fish farmers were using ICTs for. The last part of the questionnaire looked at the amount fish farmers were willing to pay for improved ICTs. Farmers were asked question on; whether they are okay with existing technologies used in the face of COVID-19, if they are willing to pay for new technologies such as agric. Mobile app, web portal, interactive whiteboard, information kiosks, video conferencing and interactive voice response system, and amount they are willing to pay for these technologies (maximum and minimum amount).

The data collected was processed and stored using Microsoft Excel and StataSE13.0 for the analysis. The data was analysed using descriptive statistics (frequency, percentage, mean, standard deviation, and chi-square) for the socioeconomic characteristics of fish farmers. Socioeconomic characteristics, usage, the extent of use, and effectiveness of ICTs use were used to predict farmer's willingness to pay for improved ICTs through the use of probit regression.

\subsection{Model Specification}

\subsubsection{Kendall's Coefficient of Concordance}

Kendall's coefficient of concordance, which is normally denoted by W, measures the level of agreement between observations (Gisev, Bell \& Chen, 2013). It bears resemblances to the spearman's rank correlation coefficient. It considers all observations of the study. The Kendall's equation is stated as;

$$
\mathrm{W}=\frac{12 \mathrm{~s}}{\mathrm{p}^{2}\left(\mathrm{n}^{3}-\mathrm{n}\right)-\mathrm{pT}}
$$

where, S: Sum of squares from row sum of ranks $\mathrm{R}_{\mathrm{i}}$; $\mathrm{n}$ : Number of objects; $\mathrm{p}$ : The number of judges; $\mathrm{T}$ : Correction factor for tied ranks. 
Therefore,

$$
\begin{gathered}
\mathrm{S}=\sum_{\mathrm{i}-1}^{\mathrm{n}} \mathrm{R}_{\mathrm{i}}^{2}-\mathrm{SSR} \\
\mathrm{T}=\sum_{\mathrm{k}-1}^{\mathrm{m}}\left(\mathrm{t}_{\mathrm{k}}^{3}-\mathrm{t}_{\mathrm{k}}\right)
\end{gathered}
$$

where, $\mathrm{m}$ : Number of groups; $\mathrm{t}_{\mathrm{k}}$ : the number of tied ranks in each $\mathrm{k}$ of $\mathrm{m}$ groups.

\subsubsection{Probit Regression}

Probit model is a binary regression model that treats the dependent as two-value outcome. The dependent variable shows if "an event will happen" being 1 or "not" being zero. The model follows the cumulative normal probability distribution. The binary outcomes are mutually exclusive and exhaustive so that no one person can be in two categories. The dependent variable in this study was willingness to pay and this was captured as "willing to pay" being 1 or "not willing to pay" for improved technologies. The dependent variable depends on $\mathrm{k}$ observable variables $X_{k}$, where $\mathrm{k}$ lies between 1 to $\mathrm{a} \mathrm{k}^{\text {th }}$ term. The probit model for the study employed the probit link function in estimation. The Maximum Likelihood Estimation technique (MLE) was used in the study to estimate the parameters of the probit model. The use of the MLE technique was to choose parameters with high probability of obtaining the farmers willingness to pay.

The probit regression model is specified mathematically as;

$$
\mathrm{Y}^{*}=\sum_{\mathrm{i}=1}^{\mathrm{k}} \mathrm{B}_{\mathrm{k}} \mathrm{X}_{\mathrm{k}}+\varepsilon, \varepsilon=\mathrm{IN}\left(0, \theta^{2}\right)
$$

where, $Y^{*}$ is a latent, unobserved continuous variable.

Hence, the dummy variable, $\mathrm{Y}$ observed and determined as;

$$
\mathrm{Y}=\left\{\begin{array}{l}
1, \text { willing to pay } \\
0, \text { not willing to pay }
\end{array}\right.
$$

The point of reference refers to the probability that $Y=1$.

If $\mathrm{Y}=1$, then;

$$
\text { Prob } \begin{aligned}
(\mathrm{Y}=1) & =\operatorname{Prob}\left(\sum_{\mathrm{i}=1}^{\mathrm{k}} \mathrm{B}_{\mathrm{k}} \mathrm{X}_{\mathrm{k}}+>0\right) \\
& =\operatorname{Prob}\left(\varepsilon>0-\sum_{\mathrm{i}=1}^{\mathrm{k}} \mathrm{B}_{\mathrm{k}} \mathrm{X}_{\mathrm{k}}\right)
\end{aligned}
$$

Since probit function follows a cumulative normal distribution function, then;

$$
=1-\Phi\left(-\sum_{\mathrm{i}=1}^{\mathrm{k}} \mathrm{B}_{\mathrm{k}} \mathrm{X}_{\mathrm{k}}\right)
$$

\begin{tabular}{|c|c|c|c|c|}
\hline & Variables & Unit of measurement & Expected Direction & Mean \pm SD \\
\hline Dependent Variable & Willingness to pay & 1-Willing to pay; 0-Not willing to pay & & \\
\hline \multirow{14}{*}{ Independent Variables } & Age & Years & - & \multirow[t]{2}{*}{$37.85 \pm 6.39$} \\
\hline & Sex & 1-Male; 0-Female & $+/-$ & \\
\hline & Scale of operation & 1-Small; 2-Medium; 3-Large & - & \multirow[t]{4}{*}{$1.33 \pm .57$} \\
\hline & Ethnicity & 1-Yoruba; 2-Igbo; 3-Others & $+/-$ & \\
\hline & Access to credit & 1-Yes; 0-No & + & \\
\hline & Religion & 1-Christian; 2-Muslim; 3-Traditional & $+/-$ & \\
\hline & Extent of usage & Measured as continuous variable & + & \multirow[t]{2}{*}{$23.15 \pm 4.68$} \\
\hline & Status & Position in the household & + & \\
\hline & Farm size & Land size in acres & + & $1.66 \pm 1.89$ \\
\hline & Effectiveness of ICT & Measured as a continuous variable & + & \multirow[t]{2}{*}{$22.45 \pm 4.91$} \\
\hline & Usage of ICT & 1 -Yes; 0-No & + & \\
\hline & Household size & Number of people under a roof & - & $4.50 \pm .91$ \\
\hline & Years of education & Years & + & $16.34 \pm 3.80$ \\
\hline & Years of farming Experience & Years & + & $8.81 \pm 3.53$ \\
\hline
\end{tabular}

Summary;

$$
\mathrm{Y}=\ln \left(\frac{\mathrm{p}}{1-\mathrm{p}}\right)=\sum \mathrm{X}_{\mathrm{i}} \beta+\varepsilon
$$

where, $Y=\left\{\begin{array}{l}1, \text { willing to payn } \\ 0, \text { not willing to pay }\end{array} ; X_{i}=\right.$ Socio-economic characteristics, usage, the extent of use and effectiveness of ICTs; $\varepsilon$ : Error term.

Table 1. Descriptive statistics 


\section{Result}

\subsection{Socioeconomic Characteristics of Fish Farmers}

The socioeconomic characteristics of fish farmers were displayed in Table 2. The table revealed that the majority of fish farmers were operating on a small scale $(72.5 \%)$ with only $(5.0 \%)$ operating on a large scale. This is attributed to the fact that fish farmers have limited access to land and capital to move production to a large scale. On the issue of COVID-19 affecting fish farmers, it was revealed that the majority of the farmers agreed that COVID-19 had affected their operation (Yes at $80 \%$ ) while $20 \%$ said "No" it has not affected them.

Furthermore, $55 \%$ of farmers agreed to the use of ICTs for various farming activities. Fish farmers as at the time of this research were using ICTs like mobile phones, TV, radio, and video conference tools for mainly marketing and getting in touch with extension agents and customers (buyers and sellers). Lastly, Table 2 revealed that fish farmers did not have access to agricultural extension agents (No at $82.5 \%$ ). This is as a result of the government restriction on free movement which made it difficult for both extension agents and farmers to have direct contact. In most farms, farmers reported that the absence of an extension agent led to losses in output.

Table 2. Socioeconomic characteristics of fish farmers

\begin{tabular}{|c|c|c|}
\hline Socioeconomic characteristics & Freq. & $\%$ \\
\hline \multicolumn{3}{|l|}{ Scale of operation(Scale) } \\
\hline Small & 29 & 72.5 \\
\hline Medium & 9 & 22.5 \\
\hline Large & 2 & 5.0 \\
\hline \multicolumn{3}{|l|}{ Affected COVID-19 } \\
\hline Yes & 32 & 80.0 \\
\hline No & 8 & 20.0 \\
\hline \multicolumn{3}{|l|}{ ICT use } \\
\hline Yes & 22 & 55.0 \\
\hline No & 18 & 45.0 \\
\hline \multicolumn{3}{|l|}{ Agricultural Extension Agent (AEA) } \\
\hline Yes & 7 & 17.5 \\
\hline No & 33 & 82.5 \\
\hline Total & 40 & 100.0 \\
\hline
\end{tabular}

\subsection{ICTs and Their Uses by Farmers}

Table 3 shows the various operations that fish farmers undertook using ICTs. The categorisation was made as production, marketing, communication, and information. It was revealed that some ICTs aided in all categories like Web Portals/Website. Agric. Mobile App aided in the production, marketing, and information. Mobile phone/Tablet and Computer/Laptop aided in marketing and communication only with Expert Systems (video conference/Teleconferencing) and Interactive Voice Response systems aiding in communication only. ICTs used for information only included; Radio, TV, Interactive whiteboards, and information kiosks.

Table 3. ICTs and their uses by farmers

\begin{tabular}{llll}
\hline Production & Marketing & Communication & Information \\
\hline Agric. Mobile App & Agric. Mobile App & Mobile phone/Tablet & Radio \\
Web Portals/Website & Web Portals/Website & Computer/Laptop & TV \\
& Mobile phone/Tablet & Web Portals/Website & Agric. Mobile App \\
& Computer/Laptop & Expert Systems (Video conference/Teleconferencing) & Web Portals/Website \\
& & Interactive Voice Response System & Information Kiosks \\
& & Interactive Whiteboard \\
\hline
\end{tabular}

\subsection{Fish Farmers' Usage of ICTs During COVID-19}

From Table 4, it was revealed that fish farmers were using both traditional and advanced ICTs for their operations. The result showed that fish farmers are still more into the usage of traditional ICTs compared to 
advanced ICTs like videoconferences, information kiosks, and interactive voice response systems, and web portals. The most used ICT was the mobile phone/Tablet (Yes at 97.5\%). Radio (Yes at 95.0\%), Television (TV) (Yes at $90.0 \%$ ) followed this, computer/Laptop (Yes at 42.5\%) with interactive voice response system and interactive whiteboard being the least used (Yes at 2.5\%). This shows that gradually fish farmers are becoming aware of improved ICTs despite traditional ICTs being used the most.

Table 4. Fish farmer's usage of ICTs during COVID-19

\begin{tabular}{llc}
\hline & \multicolumn{2}{c}{ Usage } \\
\cline { 2 - 3 } ICTs & \multicolumn{2}{c}{ Yes } \\
\cline { 2 - 3 } & Freq. & \% \\
\hline Radio & 38 & 95.0 \\
TV & 36 & 90.0 \\
Mobile phone/Tablet & 39 & 97.5 \\
Computer/Laptop & 17 & 42.5 \\
Agric. Mobile App & 6 & 15.0 \\
Web Portals/Website & 6 & 15.0 \\
Interactive Whiteboard & 1 & 2.5 \\
Information Kiosks & 3 & 7.5 \\
Expert Systems (Video conference/Teleconferencing) & 2 & 5.0 \\
Interactive Voice Response System & 1 & 2.5 \\
\hline
\end{tabular}

\subsection{Fish farmers Extent of ICTs Usage}

Table 5 looked at the usage of ICTs by farmers during COVID-19. It was revealed that fish farmers were using mobile phones/Tablets mostly with an average score of 5.42. TV (4.32) overtook radio (4.32) to the second most used ICT. The major changes experienced in the extent of use came from the interactive whiteboard which was rank last in usage but $6^{\text {th }}$ in the extent of use. The least used ICT was the expert system (video conference/teleconferencing) (1.03). This shows that fish farmers are recognising the benefit that comes with these advanced ICTs used. The model diagnostic test showed a $67.1 \%$ agreement among fish farmers considering the extent of use of ICTs. Furthermore, that there is a significant difference in the extent of ICT used by fish farmers $\left(\chi^{2}=229.446\right)$.

Table 5. Extent of ICTs usage using Kendall's coefficient of concordance

\begin{tabular}{llll}
\hline ICTs & Mean & Mean Rank & Rank \\
\hline Radio & 4.00 & 7.74 & $3^{\text {rd }}$ \\
TV & 4.32 & 7.97 & $2^{\text {nd }}$ \\
Mobile phone/Tablet & 5.42 & 9.34 & $1^{\text {st }}$ \\
Computer/Laptop & 2.39 & 5.76 & $4^{\text {th }}$ \\
Agric. Mobile App & 1.32 & 4.13 & $6^{\text {th }}$ \\
Web Portals/Website & 1.42 & 4.42 & $5^{\text {th }}$ \\
Interactive Whiteboard & 1.18 & 3.99 & $6^{\text {th }}$ \\
Information Kiosks & 1.16 & 3.96 & $7^{\text {th }}$ \\
Expert Systems (Video conference/Teleconferencing) & 1.03 & 3.80 & $9^{\text {th }}$ \\
Interactive Voice Response System & 1.05 & 3.88 & $8^{\text {th }}$ \\
\hline
\end{tabular}

Note. $\mathrm{n}=40$ Kendall's; $\mathrm{W}=.671 ;$ Chi-square $=229.446 ; \mathrm{df}=9 ;$ Asymp.sig. $=.000$.

$H_{0}$ : There is no significant relationship between improved ICTs fish farmers are willingness to pay for and scale of operation.

Table 6 looked at the farmer's willingness to pay for improved ICTs as against the scale of operation. It was revealed that the ICT requirement of farmers was evenly distributed across the scale of operations. As small-scale farmers required simple ICTs, medium to large-scale farmers required more sophisticated ICTs. An in-depth look at the results of Table 5 revealed that relative to the scale of operation farmers were willing to pay for improved ICTs. For small-scale fish farmers, the majority required information kiosks with medium-scale 
farms wanting interactive voice response systems. Large farms on the other hand required both interactive voice response systems and expert systems (video conference and teleconferencing).

A test of relationship in between improved ICTs fish farmers are willingness to pay for as against the scale of operations showed a significant relationship at $10 \%\left(\chi^{2}=.077\right)$. This implies that we reject the null hypothesis of no significant relationship between willingness to.

Table 6. Cross Tabulation of improved ICTs and scale of operations

\begin{tabular}{lllll}
\hline ICTs & Small & Medium & Large & $\chi^{\mathbf{2}}$ \\
\hline Agric. Mobile App & 2 & 1 & 0 & $\mathbf{. 0 7 7}^{*}$ \\
Mobile phone/Tablet & 3 & 1 & 0 & \\
Web Portals/Website & 0 & 1 & 0 & 1 \\
Interactive Voice Response System & 1 & 4 & 0 \\
Interactive Whiteboard & 0 & 1 & 0 \\
Information Kiosks & 4 & 0 & 0 \\
Internet connection & 2 & 1 & 1 \\
Expert Systems(Video conference/Teleconferencing) & 0 & 0 & \\
\hline
\end{tabular}

Note. ${ }^{*}$ Significant at $10 \%$.

\subsection{Amount Farmers Are Willing to Pay for Improved ICTs During COVID-19}

Table 7 looks at the amount fish farmers are willing to part away with to obtain improved ICTs during the COVID-19 period. This was done by looking at the amount with regard to the scale of operations. It was revealed that the amount fish farmers will be willing to pay for improved ICTs was not evenly distributed across the scale of operations. Table 7 shows that small and medium-scale farmers were willing to pay N 500-49900 for an improved ICT. While large scale fish farmers were willing to pay N 200000-249000 and above N 249000 for an improved ICTs. The difference in amount farmers are willing to pay is due to the economies of scale enjoyed by large-scale fish farms.

Table 7. Amount farmers are willing to pay for improved ICTs during COVID-19

\begin{tabular}{lllll}
\hline Scale of operation $(\mathbf{N})$ & Small & Medium & Large & $\chi^{\mathbf{2}}$ \\
\hline $500-49900$ & 8 & 3 & 0 & $\mathbf{. 0 5} 7^{*}$ \\
$50000-99900$ & 1 & 0 & 0 & \\
$100000-149900$ & 0 & 2 & 0 & \\
$150000-199900$ & 1 & 1 & 0 & \\
$200000-249000$ & 1 & 2 & 1 & \\
Above 249000 & 0 & 0 & 1 & \\
\hline
\end{tabular}

Note. ${ }^{*}$ Significant at $10 \%$.

\subsection{Factors Predicting Farmer's Willingness to Pay for Improved ICTS}

Table 8 shows the factors that influence farmer's willingness to pay for improved ICTs. The independent variables used were made up of socioeconomic variables and other variables like usage of ICTs, the effectiveness of ICTs, and extent of usage of ICTs with the dependent variable being willingness to pay for improved ICTs. The diagnostic test of the model shows that the model is significant at $1 \%$ with the independent variables explaining the dependent variable by $54.2 \%$. This shows that the independent variables used for the study are good fit for the model.

An in-depth look at the variables shows that only five (5) variables (scale of operation, age, household size, and status in household and usage of ICT) were significant predictors of fish farmer's willingness to pay for improved ICTs. With the scale of operations, it was revealed that fish farmer's likelihood of being willing to pay for improved ICTs decreased marginally by $46 \%$ as their scale of operation increases. This is true because, during the period of COVID-19, farmers had to reduce their scale of operation to minimise the cost of operation given that farmers did not have access to inputs like raw materials, funds, and few number of workers to mount machines and perform other jobs in the farm. In large farms, workers have to practice the shift system, which 
requires less number of workers at a time with close to $40 \%$ being laid off. For age, it was revealed that that as fish farmers age their willingness to pay for improved ICTs falls by $30 \%$. This is as a result of the fact that the majority of these fish farmers had a lot of financial responsibilities attached to being old. Therefore, purchasing improved ICTs was not lucrative to them despite the benefit these ICTs carry. Also in Table 8, it was revealed that as the size of a fish farmer household increases, the willingness to pay for improved ICTs of the farmer falls by $48.9 \%$. This is simply because fish farmer's financial resources were overstretched during the COVID-19 period with survival being their primary motive. Therefore improved ICTs did not look attractive to them during the period.

Furthermore, fish farmers who were the head of the households saw their willingness to pay for improved ICTs fall by $29.7 \%$ during the COVID-19 period. This was mainly because, in most households of fish farmers, the household depends solely on the resource of the head, and therefore purchasing of improved ICTs becomes unattractive to them. Lastly, on the usage of ICTs, it was revealed in Table 8 that fish farmers who already were using some form of ICTs had their willingness to pay for improved ICTs increase by $9.5 \%$.

Table 8. Factors influencing farmer's willingness to pay for improved ICTs

\begin{tabular}{llllll}
\hline Wtp1 & $\mathbf{d y} / \mathbf{d x}$ & Robust Std. Err. & $\mathbf{z}$ & $\mathbf{P}>|\mathbf{z}|$ & {$[\mathbf{9 5 \%}$ Conf. Interval] } \\
\hline size_farm & 0.016 & 0.018 & 0.860 & 0.391 & -0.020 \\
Credit & -0.224 & 0.250 & -0.900 & 0.370 & -0.714 \\
Scale & $-0.460^{* *}$ & 0.225 & -2.050 & 0.041 & -0.900 \\
Age & $-0.301^{* *}$ & 0.110 & -2.730 & 0.006 & -0.517 \\
Household size & $-0.489^{* *}$ & 0.103 & -4.750 & 0.000 & -0.691 \\
Sex & 0.040 & 0.146 & 0.270 & 0.785 & -0.246 \\
Ethnicity & 0.189 & 0.285 & 0.660 & 0.507 & -0.369 \\
Status & $-0.297^{* *}$ & 0.122 & -2.430 & 0.015 & -0.537 \\
Farming Experience & 0.062 & 0.092 & 0.670 & 0.500 & -0.118 \\
Level of education & -0.021 & 0.024 & -0.860 & 0.391 & -0.068 \\
Religion & 0.035 & 0.166 & 0.210 & 0.831 & -0.290 \\
Extent & 0.050 & 0.033 & 11.530 & 0.125 & -0.014 \\
Effective & -0.021 & 0.032 & -0.670 & 0.505 & -0.084 \\
Usage & $0.095^{* *}$ & 0.043 & 2.230 & 0.026 & 0.011 \\
n & 40 & & & & \\
Wald chi2 (14) & 40.16 & & & & \\
Prob chi2 & 0.000 & & & & \\
Pseudo R2 & 0.542 & & & & \\
Log pseudolikelihood & 12.069 & & & & \\
\hline
\end{tabular}

Note. ${ }^{* *}$ Significant at $5 \%$.

\section{Discussion}

\subsection{Socioeconomic Characteristics of Fish Farmers}

The classification of farm size as small, medium and large was based on Nigeria National Bureau of Statistics (2011). It classified small-scale farm size as $<3$ hectares, medium as 3-7 hectares and large farm size as more than 7 hectares. In the same report, it was revealed that more than half of fish farms in Nigeria were operating on small to medium scale. Attah, Otene and Waya (2020) added that majority of fish farmers had their farms being few meters away from their houses of at most 1 acre due to land-related dispute and the government restriction on free movement, which made access to large farms difficult. Purkait et al. (2020) who also reported that fish farmers have been affected by the pandemic with the major areas of fish farmers business affected being market access (both input and output market), production, and access to extension agents. Lastly, on ICT use by farmers, the result of this study were consistent with Folasade, Gaius and Dare (2021) who also reported that fish farmers during the COVID-19 period were using mostly traditional ICTs for their fish farming operations.

\subsection{ICTs and Their Uses by Farmers}

The study findings support George and Akinrotimi (2021) view that the introduction of online marketing in the face of curfew has push fish farmers to adopt ICTs that enable them to get into contact with markets and information regarding input and output outlets. However, Emaziye and Ovharhe (2021) held that, the use of ICTs 
for communication is traditional, as ICTs purchased by farmers should have their core aim addressing communication.

\section{3 Fish Farmers' Usage of ICTs During COVID-19}

The results supports Burade et al. (2020) and Afolabi, and Tiamiyu (2021) who also confirmed that fish farmers are mainly using traditional ICTs like radio, TV, and mobile phones for their fish farming operations but there are tiny traces of advanced ICT being introduced especially by large-scale fish farms.

\subsection{Fish farmers Extent of ICTs Usage}

The results of this study contradict Aphunu and Atoma (2011) and Eucharia et al. (2016) who reported that TV was the most frequently used ICTs by fish farmers. The same study rated radio second most used ICT by fish farmers. Mobile Phone that was discovered in this study as ranked first was third in their study.

\subsection{Factors Predicting Farmer's Willingness to Pay for Improved ICTS}

The findings of this study pointed to farmers already knowing the benefit that ICTs offers to them as farmers. Similar studies done on willingness to pay for improved ICTs by fish farmers revealed that; age, farming experience, farm size, and education were found to be significant to influencing farmer's willingness to pay for ICTs (Zheng et al., 2018). Chitate (2018) in his thesis reported that only age and farm size were significant in influencing willingness to pay for ICTs. While, Yi (2019) studies on willingness to pay for ICTs by fish farmers revealed that only credit was significant. For Ifejika et al. (2015) studies in Nigeria on farmer's willingness to pay for ICTs they revealed that age, education, and farming experience were not significant to influencing farmer's willingness to pay for ICTs. This shows that factors influencing fish farmers' willingness to pay for ICTs are evolving and also situational led.

\section{Conclusions}

In conclusion, the study revealed that fish farmers' farming activity has been affected by the outbreak of the COVID-19 pandemic. The major effect was felt by farmers in the procurement of input, output sales, and contact with service providers like extension agents due to COVID-19 restrictions imposed on the state like restricted movement and social distancing. The study revealed that fish farmers use ICT tools mostly for communication and marketing purposes due to the imposition of curfew by the government in Ibadan and the need to get to target customers, input dealers, and extension agents on time. Furthermore, mobile phone was observed to be the most used ICT tool by fish farmers during the period of the pandemic. The study also revealed that the need for improved ICTs differs in terms of the scale of operations. As small-scale farmers preferred paying for information kiosks, medium scale were willing to pay for interactive voice response systems with large-scale farmers adding expert systems and interactive voice response systems. This makes it evident that farmers during COVID-19 were more interested in ICTs which enhance connectivity to clients and business partners. It was also concluded that socioeconomic characteristics of farmers like age, household size, status in the household, and usage of ICTs play a vital role in farmer's willingness to pay for improved ICTs.

The study recommends that the government, the ministry for aquaculture, and stakeholders in aquaculture should support small-scale fish farmers in the form of training, credit and provision of support systems to help them acquire and use improved ICTs. Secondly, the IT firms should produce age friendly ICTs to help aged fish farmers in their operation since they form the majority of fish farmers. The ministry for aquaculture, and stakeholders in aquaculture should educate heads of households on the need to adopt improved ICTs in their operations despite having large household size Also, the government should give farmers who are willing to use improved ICTs subsidies to ease the financial burdens associated with these ICTs. Lastly, the development of these improved ICTs should be farmer-friendly and also take into consideration their varying socioeconomic characteristics.

\section{Reference}

Afolabi, S. O., \& Tiamiyu, M. A. (2021). Information use behaviour of sedentary livestock farmers in egbeda local government area of oyo state, Nigeria. Library Philosophy and Practice, 1-14.

Aphunu, A., \& Atoma, C. N. (2011). Extent of use of ICTs by fish farmers in Isoko Agricultural Zone of Delta State. Journal of Agricultural Extension, 15(1), 28-39. https://doi.org/10.4314/jae.v15i1.2

Attah, A. J. (2020). Assessment of Internet And Mobile Phone Usage in. International Journal of Research and Scientific Innovation, VII( III), 2321-2705. 
Attah, A. J., Otene, V. A., \& Waya, D. (2020). Assessment of Internet And Mobile Phone Usage in Makurdi Local Government Area of Benue State, Nigeria. International Journal of Research and Scientific Innovation, VII(III), 1-7.

Burabe, B. I., Thliza, M. G., Owolabi, J. O., \& Saleh, R. A. (2020). Assessment of the Effectiveness of Utilization of Electronic Media Among Fish Farmers in Maiduguri Metropolis, Borno State, Nigeria. Journal of Agricultural Economics, Environment and Social Sciences, 6(2), 7-15.

Chavula, H. K. (2014). The role of ICTs in agricultural production in Africa. Journal of Development and Agricultural Economics, 6(7), 279-289. https://doi.org/10.5897/JDAE2013.0517

Chitate, T. (2018). An assessment of dairy farmer's willingness to pay for government based extension services. A case of Goromonzi and Chikomba Districts in Mashonaland East Province of Zimbabwe (Doctoral dissertation, Bindura University of Science Education, Zimbabwe).

Emaziye, P. O., \& Ovharhe , O. J. (2021). Profitability analysis of fish selling in isoko south. Russian Journal of Agricultural and Socio-Economic Sciences, 1(109), 1-6. https://doi.org/10.18551/rjoas.2021-01.15

Eucharia, E., Ngozi, U., Chikaire, J., Ifeanyi, O. E., \& Patience, C. N. (2016). Roles of Information and Communications Technologies in improving fish farming and production in Rivers State, Nigeria. Library Philosophy and Practice, 1(1), 14-45.

Folasade, O. O., Gaius, O. O., \& Dare, A. (2021). Impact of information communication technology (ict) and mass media usage on technical efficiency of fish farming in Ogun state, Nigeria. Journal of Agribusiness and Rural Development, 2(60), 143-150. https://doi.org/10.17306/J.JARD.2021.01378

FAO (Food and Agricultural Organization of the United Nations). (2017). Information and Communication Technology (ICT) in Agriculture (A Report to the G20 Agricultural Deputies). Rome, Italy: FAO.

Getahun, A. A. (2020). Challenges and opportunities of information and communication technologies for dissemination of agricultural information in Ethiopia. International Journal of Agricultural Extension, 8(1), 57-65. https://doi.org/10.33687/ijae.008.01.3069

George, A. I., \& Akinrotimi, O. A. (2021). Evaluation of Fish Marketing Strategies in Obio Akpor Local Government of Rivers State, Nigeria. Quest Journals, 7(2), 55-59.

Gisev, N., Bell, J. S., \& Chen, T. F. (2013). Interrater agreement and interrater reliability: key concepts, approaches, and applications. Research in Social and Administrative Pharmacy, 9(3), 330-338.

Ifejika, P. I., Oladosu, I. O., Asadu, A. N., Ayanwuyi, E., Sule, A. M., \& Tanko, M. (2015). Assessment of aquapreneur willingness to pay for mobile phone advisory services in anambra state, Nigeria. International Journal of Agriculture and Forestry, 5(6), 330-338. https://doi.org/10.1016/j.sapharm.2012.04.004

Nigeria National Bureau of Statistics. (2011). Fish farm size distribution in Nigeria. Retrieved October 30, 2021, from https://www.nigerianstat.gov.ng

Otsuka, K., Kijima, Y., \& Sserunkuuma, D. (2011). An inquiry into constraints on a green revolution in Sub-Saharan Africa: the case of NERICA rice in Uganda. World Development, 39(1), 77-86. https://doi.org/ 10.1016/j.worlddev.2010.06.010

Purkait, S., Karmakar, S., Chowdhury, S., Mali, P., \& Sau, S. K. (2020). Impacts of novel coronavirus (COVID-19) pandemic on fisheries sector in India: A Minireview. Ind. J. Pure App. Biosci, 8(3), 487-492. https://doi.org/10.18782/2582-2845.8179

Yi, S. (2019). Willingness-to-pay for sustainable aquaculture products: Evidence from Korean red seabream aquaculture. Sustainability, 11(6), 15-77. https://doi.org/10.3390/su11061577

Zheng, H., Mu, H., \& Zhao, X. (2018). Evaluating the demand for aquaculture insurance: An investigation of fish farmers' willingness to pay in central coastal areas in China. Marine Policy, 96(1), 152-162. https://doi.org/10.1016/j.marpol.2018.08.021

\section{Copyrights}

Copyright for this article is retained by the author(s), with first publication rights granted to the journal.

This is an open-access article distributed under the terms and conditions of the Creative Commons Attribution license (http://creativecommons.org/licenses/by/4.0/). 